\title{
The Development Trend of Cultural Added Value Research Based on Big Data Analysis
}

\author{
Ni Yuan ${ }^{1 \mathrm{a}}$ Yang Lu ${ }^{1 \mathrm{~b}}$ Gao Yudong ${ }^{1 \mathrm{c}}$ Cai Gongshan ${ }^{1 \mathrm{~d}}$ \\ ${ }^{1}$ Beijing Information Science and Technology University \\ Graduate school of economics and management \\ Beijing, China
}

\begin{abstract}
Cultural added value refers to the value added generated by the combination of cultural elements and different forms of carrier. It shapes the uniqueness of cultural products, not only satisfies the cultural spiritual enjoyment of consumers and helps enterprises build a unique cultural brand image, but also promotes excellent traditional culture and spreads positive cultural values. However, its research is still in an initial stage. The relevant concepts and context are not clear enough and lack of systematic combing. Therefore, this paper takes 354 relevant articles as data samples for the following analysis. Firstly, we used the method of bibliometric analysis to sort out its publishing trend and regional distribution. Secondly, we used social network analysis method to identify research hotspots in this field and analyzed its evolution trend. Thirdly, cluster analysis was used to identify relevant research topics in the field of cultural appreciation, and literature review was conducted around these three clustering topics. Finally, the future research direction of this field is proposed based on the above contents.
\end{abstract}

\section{Introduction}

The rapid development of Internet technology leads a trend of digital economy. In the new era, the cultural and creative industry is gradually going digital and intelligent, bringing people different cultural experience. Culture carries the blood of national development and is also an important indicator of the overall strength of a country. Chinese culture presents itself to the people of the world with a new face in various forms, such as films, novels and TV programs. China's "The Belt and Road" strategy actively promotes Chinese culture to "going out", so that China's voice in the cross-cultural communication strategy enhanced. Internet the Internet is a carrier for spreading excellent culture and promoting positive energy. The "Internet plus" wave has broken the boundaries of traditional fields and achieved cross-boundary cultural integration. "Culture + tourism", "culture +IP" and other "culture + " new business models emerge at the historic moment ${ }^{[1]}$.

The cultural added value of products can meet people's demand for culture and improve customer loyalty, which has become one of the critical approaches for businesses to win the consumer's favor ${ }^{[2]}$. At present, the cultural innovation mode with cultural value-added as the core has become the mainstream trend of the development of cultural innovation industry. Since the 18th national congress of the communist party of China(CPC), the state has issued a series of documents repeatedly emphasizing the importance of cultural added value. The formation of communication platforms such as Confucius institutes has also actively advocated the study of cultural added value, and more and more scholars are exploring this field. In view of this, this paper will focus on the study of cultural value added. First, CNKI database was used as the data source. Then, through the integration of a variety of measurement methods, the research status and the evolution of research contents in this field were understood. Finally, relevant research topics of cultural added value were identified by summarizing and analyzing.

\section{2 data acquisition}

In this study, the advanced search criteria were set in the CNKI database, and the search terms of subject, keyword, abstract and article name were set as "Cultural Added Value" respectively. The relationship between the four search criteria was "or". Because scholars published few literatures in the field of cultural value added, in order to ensure the comprehensiveness of data, this paper selected all journals as the source category and obtained 1103 articles. In addition, we manually judged the literature and some non-academic papers that were mentioned in the

\footnotetext{
ae-mail: niyuan230@163.com be-mail: 1046062198@qq.come-mail:13161639206@163.com de-mail: 1033117679@qq.com
} 
text but were not directly related to cultural value-added content, such as conference submissions, submission instructions, etc. Finally, we selected 354 Chinese literatures as samples for analysis.

\subsection{Research Design}

This article combines literature measurement, visual analysis, social network analysis and other methods to analyze the status of cultural added value research ${ }^{[3-5]}$. The research ideas and technical route are shown in Figure 1. Firstly, the literature bibliometric software Bicomb2 was used to conduct frequency statistics on the number of articles, research institutions and keywords of the selected literature. Secondly, Excel software was used to draw the trend chart of publication volume. According to the variation trend of publication volume, the literature in this field was divided into three stages for comparison, and the number of keywords in different stages and their cumulative percentage were counted to analyze the evolution of the research content ${ }^{[6]}$. Finally, the software Pajek was used to draw a network map of keywords and discover research hotspots in related fields.

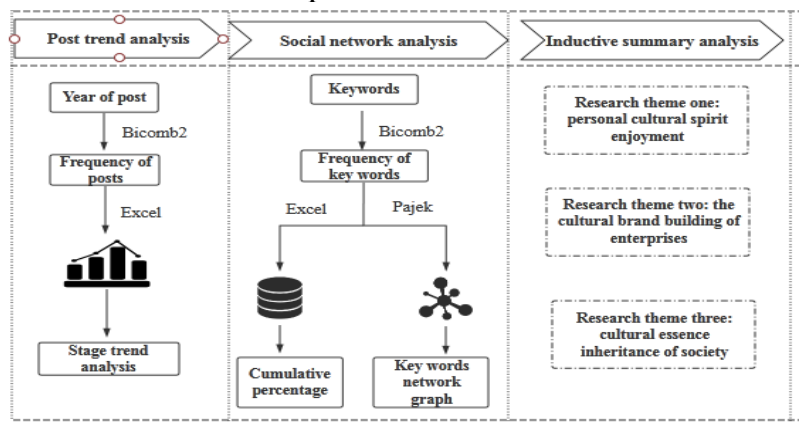

Figure 1. Study the technical route diagram

\section{Research Overview of Cultural Added Value}

\subsection{Post trend analysis}

The changes in the number of publications in the field of cultural added value in China in the past 30 years are shown in Figure 2. Add trend line regression formula as $y$ $=-0.0012 x^{4}+0.0608 x^{3}-0.9329 x^{2}+5.3971 x-5.7841$, and the determination coefficient $\left(\mathrm{R}^{2}\right)$ is 0.8042 , which Indicates that the trend line has a good fitting degree to the actual situation of the number of posts. In addition, in order to show the changes of research contents in different time periods, this paper divides the research on cultural added value into three stages: The first stage is from 1990 to 2003, and the amount of related publications basically shows an upward trend; the second stage is from 2004 to 2013, growth rate of its circulation has increased; the third stage is from 2014 to 2019, the growth rate of the amount of articles published gradually tends to level off. It can be seen that domestic scholars are paying more and more attention to this field, which is related to the national emphasis on building a strong socialist culture.

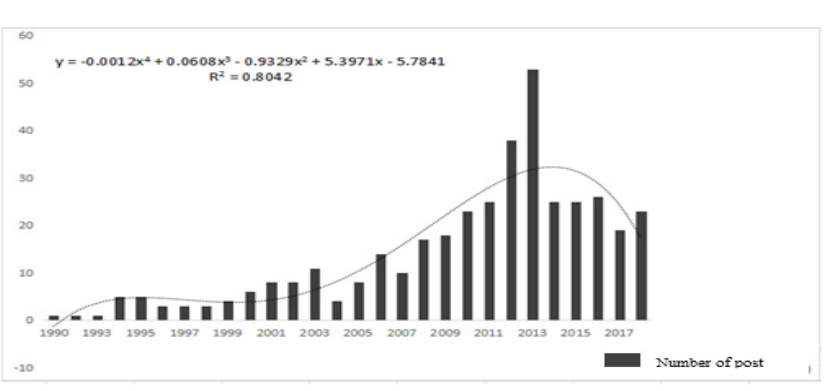

Figure 2. Statistics on the number of cultural value-added publications from 1990 to 2019

\subsection{Units Research content evolution analysis}

After a preliminary analysis of the number of publications in Figure 2, it is found that there is less research in the field of domestic value-added culture. Therefore, according to the above three stages, this paper extracts and processes keywords of literature in each time period, and lists the number of keywords with frequency greater than or equal to 2 and its cumulative percentage after removing incomplete and non-standard keywords, as shown in table 1. In terms of the number of keywords, the research contents and scope of stage 2 are relatively wide, but in terms of time interval, the number of keywords in the third stage is exactly the same as that in the first stage, which also indicates that scholars have been increasing their research on cultural added value in recent years.

TABLE I. NUMBER OF KEYWORDS WITH CUMULATIVE WORD FREQUENCY GREATER THAN OR EQUAL TO 2 AND CUMULATIVE PERCENTAGE

\begin{tabular}{|l|c|l|l|}
\hline Stage & $\begin{array}{l}\text { Stage One } \\
(\mathbf{1 9 9 0 - 2 0 0 3 )}\end{array}$ & $\begin{array}{l}\text { Stage } \\
\text { Two } \\
\mathbf{( 2 0 0 4 -} \\
\mathbf{2 0 1 3 )}\end{array}$ & $\begin{array}{l}\text { Stage } \\
\text { Three } \\
\mathbf{( 2 0 1 4 -} \\
\mathbf{2 0 1 9 )}\end{array}$ \\
\hline Quantity & 208 & 327 & 208 \\
\hline $\begin{array}{l}\text { Cumulative } \\
\text { Percentage }\end{array}$ & 48.485 & 37.402 & 35.284 \\
\hline
\end{tabular}

In order to further compare and analyze the changes of the research contents in different stages, the top 10 keywords with occurrence frequency were counted, and the results are shown in Table II ( $\mathrm{F}$ is for frequency):

The first stage: domestic scholars' research on cultural added value is mainly focused on consumers and enterprises. As cultural product is a kind of product that pays attention to the spiritual needs of consumers, the consumer's consumption process of cultural product is not only the consumption of its own function, but also the recognition of its cultural added value. Through the unique cultural value of cultural products, enterprises can satisfy consumers' self-pleasure and spiritual enjoyment and improve customer purchase intention ${ }^{[7]}$. At the same time, improving the cultural added value of goods can promote the rapid development of enterprise economy, so as to gain more economic advantages in the competitive market ${ }^{[8]}$. So scholars will pay more attention to consumers and enterprises in the research process. 
The second stage: the research hotspot in the field of cultural added value mainly focuses on culture, brand and advertisement. The 19th national congress of the communist party of China (CPC) emphasizes the need to strengthen and enhance cultural confidence, which means to give play to the advantages of China's cultural resources and highlight the cultural value ${ }^{[9]}$. However, due to the lack of brand awareness in China's cultural industry, the cultural brands created are difficult to be deeply rooted in the hearts of people and cannot be understood by them ${ }^{[10]}$. Therefore, in order to create cultural products with Chinese characteristics, it is necessary to show the unique cultural charm of China. The integration of excellent traditional cultural elements can not only increase the cultural content of the products, but also create a more profound cultural brand by means of advertising. The role of advertising is to restore people's demand. It expresses in a narrative way what consumers will be after they own the product, thus winning the favor of consumers and enhancing the value of cultural brands, which increase the international competitiveness of cultural industries, and gaining worldwide recognition ${ }^{[11][12][13]}$.

The third stage: The main research content of this field is the economic benefits of cultural added value to cultural industry and cultural creative industry. The cultural and creative industry carries China's excellent culture and takes culture as its resource and innovation as its driving force. The economic value of cultural industry is reflected in the uniqueness of its products, so the core of cultural industry is innovation, and the improvement of innovation ability is one of the channels to promote the development of cultural industry, and it is also one of the effective measures to improve the added value of product culture ${ }^{[14]}$. Considering the cultural added value of commodities, it generally starts from the trademark, name and package design of commodities, takes innovation as the orientation, and improves the identification degree of commodities through cultural creativity to meet people's cultural needs, so as to stimulate customers' consumption and achieve the purpose of improving the economic benefits of enterprises [15] [16].

TABLE II. SOME HIGH-FREQUENCY KEYWORDS

\begin{tabular}{|c|c|c|c|c|c|}
\hline \multicolumn{2}{|l|}{$\begin{array}{l}\text { Stage One } \\
(1990-2003)\end{array}$} & \multicolumn{2}{|l|}{$\begin{array}{l}\text { Stage Two } \\
(2004-2013)\end{array}$} & \multicolumn{2}{|c|}{$\begin{array}{l}\text { StageThree } \\
(2014-2019) \\
\end{array}$} \\
\hline Keywords & $F$ & Keywords & $F$ & Keywords & $F$ \\
\hline Enterprise & 14 & Culture & 23 & $\begin{array}{l}\text { Culture } \\
\text { Industry }\end{array}$ & 18 \\
\hline $\begin{array}{c}\text { Business } \\
\text { Management }\end{array}$ & 14 & $\begin{array}{c}\text { Cultural } \\
\text { Added } \\
\text { Value }\end{array}$ & 18 & $\begin{array}{c}\text { Tea } \\
\text { Culture }\end{array}$ & 9 \\
\hline $\begin{array}{l}\text { Research } \\
\text { Hotspots }\end{array}$ & 9 & Enterprise & 14 & $\begin{array}{l}\text { Research } \\
\text { Hotspots }\end{array}$ & 9 \\
\hline $\begin{array}{l}\text { Company } \\
\text { Culture }\end{array}$ & 9 & $\begin{array}{l}\text { Culture } \\
\text { Industry }\end{array}$ & 13 & $\begin{array}{l}\text { Cluster } \\
\text { Analysis }\end{array}$ & 8 \\
\hline Consumer & 8 & $\begin{array}{l}\text { Company } \\
\text { Culture }\end{array}$ & 11 & $\begin{array}{c}\text { Knowledge } \\
\text { Graph }\end{array}$ & 7 \\
\hline
\end{tabular}

\subsection{Hot research findings}

In order to find the research hotspot in the field of cultural added value, this paper uses Bicomb2 software to conduct statistics on all keywords in the document library and generate a co-occurrence matrix. To further improve the visual effect of keyword co-occurrence analysis, only 72 keywords whose word frequency is greater than and equal to 3 are selected. Pajek software is used to draw a keyword network diagram [17]. The resulting centrality level distribution diagram is shown in figure 3 . Each node in figure 3 represents a keyword. The keyword name is marked at the bottom right of the corresponding node, and the color depth of the node indicates the frequency of occurrence of the keyword in the literature. the centrality of keywords are Calculated by formula $C_{c}\left(v_{i}\right)=(N-1) /\left[\sum_{j=1, j \neq i}^{N} d_{i j}\right]$, where $C_{c}\left(v_{i}\right)$ represents centrality, $\mathrm{N}$ is the number of nodes, $\mathrm{d}_{i j}$ represents the linear distance between nodes $v_{i}$ and node $v_{j}$. The higher the centrality, the larger the node and the darker the color. On this basis, keywords are divided into three levels according to node centrality: (1) $C_{c}\left(v_{i}\right) \geq 0.55$ represents the core node $\bullet$; (2) $0.45 \leq C_{c}\left(v_{i}\right) \leq 0.55$ represents the node in the middle layer ; (3) $C_{c}\left(v_{i}\right) \leq 0.45$ represents the edge node $\circ$, and the connection between two nodes indicates that the two keywords appear together.

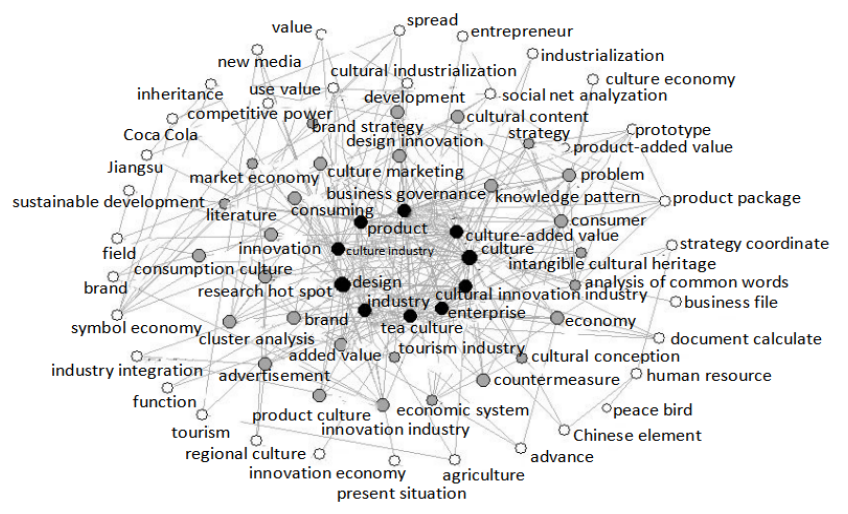

Figure 3. Keyword network graph

There are 10 keywords at the core node in Figure 3, including culture, cultural added value, cultural industries and cultural creative industries, etc, the approximate 
centrality of all of them is greater than 0.55 , accounting for $13.89 \%$ of the total. In addition, there are 28 nodes in the middle tier, including commodity culture, tourism industry and design innovation, accounting for $38.89 \%$ of the total, which indicates that attention is paid to cultural added value in commodity design and tourism industry. At the same time, it also shows the importance of innovation to cultural products, which can increase the added value of cultural industry and improve the market competitiveness of enterprises. Cultural and creative products, as a special commodity, should fundamentally meet the specific needs of consumers and promote their purchasing behavior, so that customers can get spiritual enjoyment in the process of cultural consumption, so as to achieve the purpose of cultural inheritance and inheritance ${ }^{[18]}$. There are 34 nodes on the edge layer, including regional culture, peace bird and Coca-Cola, which account for $47.22 \%$ of the total. Cultural brands can bring consumers a deeper level of cultural identity and spiritual sustenance, and cultural added value is the intangible value that brands add in various forms on the tangible value of cultural products, it is the spiritual enjoyment of consumers on the basis of material satisfaction [19]. "Brand sensitivity" is one of the psychological variables to improve consumers' purchasing behavior, and consumers' sensitivity is positively influenced by traditional culture and modern culture, which is crucial to improve consumers' brand honesty ${ }^{[20]}$. Although the centrality of the edge nodes is relatively low, they are relatively high in degree and closely related to other keywords. It is not difficult to see that the future research focus of cultural added value is gradually closer to some specific brands and regional characteristic cultures.

\section{Conclusions}

Under the promotion of digital technology, the combination of intangible cultural creativity and tangible material carrier can promote the rapid development of cultural and creative enterprise. The consumption of cultural and creative products accumulates people's deepest spiritual pursuit, and the cultural value added of product has become an important means for businesses to win the favor of consumers. The organic integration of "digital", "culture" and "platform" has resulted in a series of cultural innovation forms and new formats. They make cultural and creative products no longer simply reappear traditional culture, but use digital technology to fuse products with different cultures. Make the empty and rigid cultural symbols "live", and bring more cultural added value to the product.

Compared to products with low value of traditional culture and low innovation degree, cultural and creative products pay more attention to establishing emotional bond with consumers, and emphasize the pleasure and happiness that users can get in the process of interacting with products. Cultural and creative products, as such a special commodity, should fundamentally meet the specific needs of consumers and promote their purchasing behavior, so that customers can get spiritual enjoyment in the process of cultural consumption, so as to achieve the purpose of cultural inheritance and inheritance.

Cultural added value is still a new research field, but both the growth rate of published articles and the diversity of research content are on the rise. In this paper, literature review on the field of cultural added value was carried out by combining literature measurement, social network analysis, and summary and induction. This paper found that the research on cultural added value mainly focused on three aspects: personal cultural spirit enjoyment, enterprise cultural brand building and social cultural essence inheritance. Firstly, from a consumer standpoint, conferred by the cultural products of cultural connotations and values can greatly satisfy the consumer's growing spiritual and cultural demands, but under the different living environment and cultural quality of consumers may be different for the same product evaluation, so consumers aesthetic and emotional tendencies caused by the subjective feeling is one of the factors that affect cultural added value. Secondly, in line with the development of the times, the integration of culture and digital technology has made a breakthrough in innovative design. Combined with the network and intelligence of digital technology, the cultural products with distinctive characteristics can be created, which can improve the recognition of products and have a profound impact on the cultural brand image. Thirdly, the value of cultural and creative products is mainly reflected in the cultural value it provides, and the essence of the consumption process of cultural and creative products is the inheritance of cultural spirit.

Fund project: National Key Research and Development Program Project "Service Value and Cultural Communication Evaluation Theory and Technology"(2017YFB1400400); Beijing Youth Top Talent Cultivation Project (CIT\&TCD 20180405); General Project of Science and Technology Plan of Beijing Municipal Education Commission (SM201611232002); Diligent Letter Talent Project (QXTCPC201706).

\section{References}

1. Guo Yonghui. "Culture+ and the Rise of Cultural Industry" [j]. Red Flag Manuscript, 2015 (22): 23-26 +1 .

2. Huang Lei. Semiotic Interpretation of the Added Value of Advertising Culture [j]. Contemporary Communication, 2004 (01): 75-76.

3. Rübel O, Ahern S, Bethel E W, et al. Coupling Visualization and Data Analysis for Knowledge Discovery from Multi-Dimensional Scientific Data[J]. Procedia Comput Sci, 2010, 1(1):1757-1764.

4. Scott J. Social Network Analysis[M]. London: Sage, 2012.

5. Hansen P, Jaumard B. Cluster Analysis and Mathematical Programming [J]. Mathematical Programming, 1997, 79(1-3):191-215. 
6. Tahereh Dehdarirad, Anna Villarroya, Maite Barrios. Research Trends in Gender Differences in Higher Education and Science: A Co-Word Analysis [J]. Scientometrics, 2014, 101(01): 273- 290.

7. Gao Ling, Zhang Mengxia. Influencing Factors and Mechanism of Consumer Willingness to Purchase Non-Heritage Products [j]. Economic and Management Research, 2018, 39 (01): 126-135.

8. Wan Yougen. On the Cultural Communication Function of Commodity Packaging [j] . Solicitation, 2003 (05): 177-179.

9. Wang Yuefen, Wu Dan. Highlighting the Heritage of Traditional Culture and Enhancing Cultural SelfConfidence [j]. People's Forum, 2019 (10): 138-139.

10. Shen Si. Creating a Cultural Brand with Global Influence [j]. People's Forum, 2018 (01): 138-139.

11. Yang Hong. Brand Construction Should Pay Attention to Promoting the Cultural Value of the Brand [j]. Journal of Economic Herald, 2008 (05): 67-68.

12. Shen Si. Creating a Cultural Brand with Global Influence [j]. People's Forum, 2018 (01): 138-139.

13. Wu Wenhan. Reconstruction of the Meaning of Mass Culture in Contemporary Advertising Communication [j]. Journal of Zhengzhou University (Philosophy and Social Science Edition), 2015, 48 (02): 175-179.
14. Hang Min, Zhou Yuan. Research on the Development of Characteristic Cultural Industry from the Perspective of Innovation Clusters [j]. Media, 2018 (24): 75-80.

15. Jiang Jian. On the Cultural Value of Commodities [j]. Social Science Fronts, 2003 (02): 249-251.

16. Liu Xiaodong, Xu Qi, Feng Xinqun. Research on Added Value Strategy of Cultural Creative Products Based on Regional Cultural Research [j]. Hundred Art, 2016, 32 (03): 54-57.

17. Wouter de Nooy, Andrej Mrvar and Vladimir Batagelj. Exploratory Social Network Analysis with Pajek [M]. New York: Cambridge University Press, 2011.

18. Qian Fengde, Yin Zehe, Ding Na. Research on the Relationship between Comprehensive Evaluation and Purchase Behavior of Cultural and Creative Products [J]. Packaging Engineering, 2008, 39 (24) : 183-188.

19. Chen Yonghua, Han Shuang. Research on the Added Value Promotion of Fuxin Agate Jade Culture [j]. Journal of Liaoning Technical University (Social Science Edition), 2016, 18 (05) : 711-714.

20. Guo Xiaoling, Zhang Mengxia. Research on the Motivation of Brand's Sensitive Cultural-On the Regulating Effect of Product Benefit Attribute [J]. Research on Financial and Economic Issues, 2010 (11) : 97-105. 